\title{
Cuba, bienes funerarios y publicidad registral. Propuesta para su perfeccionamiento
}

\section{Cuba, Funerary Goods and Registries' Publicity. Improvement Proposal}

Juan Carlos Mendoza Pérez,* Dayamis Ramírez Thomas** y Gretcher Lamas Bertrán***

http://dx.doi.org/10.21503/lex.v16i22.1654

* Profesor principal de Derecho Notarial y Derecho de Obligaciones en el Departamento de Derecho de la Universidad de Guantánamo, Cuba.

Correo electrónico: jcperez@cug.co.cu

** Profesora principal de Derecho Civil Parte General y Bioética y Derecho en el Departamento de Derecho de la Universidad de Guantánamo, Cuba.

Correo electrónico: dayamisrt@cug.co.cu

*** Profesora de Derecho Notarial y Derecho de Obligaciones en el Departamento de Derecho de la Universidad de Guantánamo, Cuba.

Correo electrónico: gretcherlb@cug.co.cu

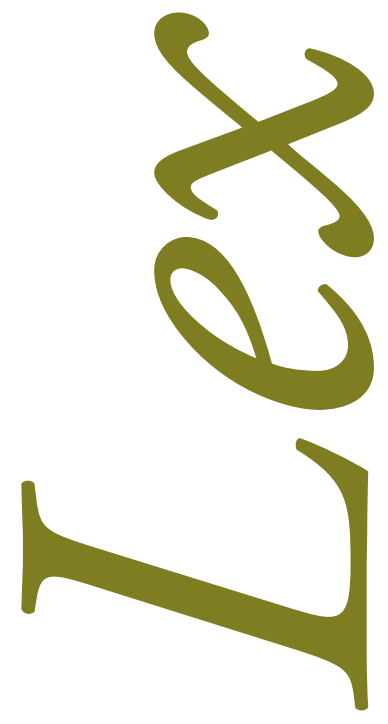




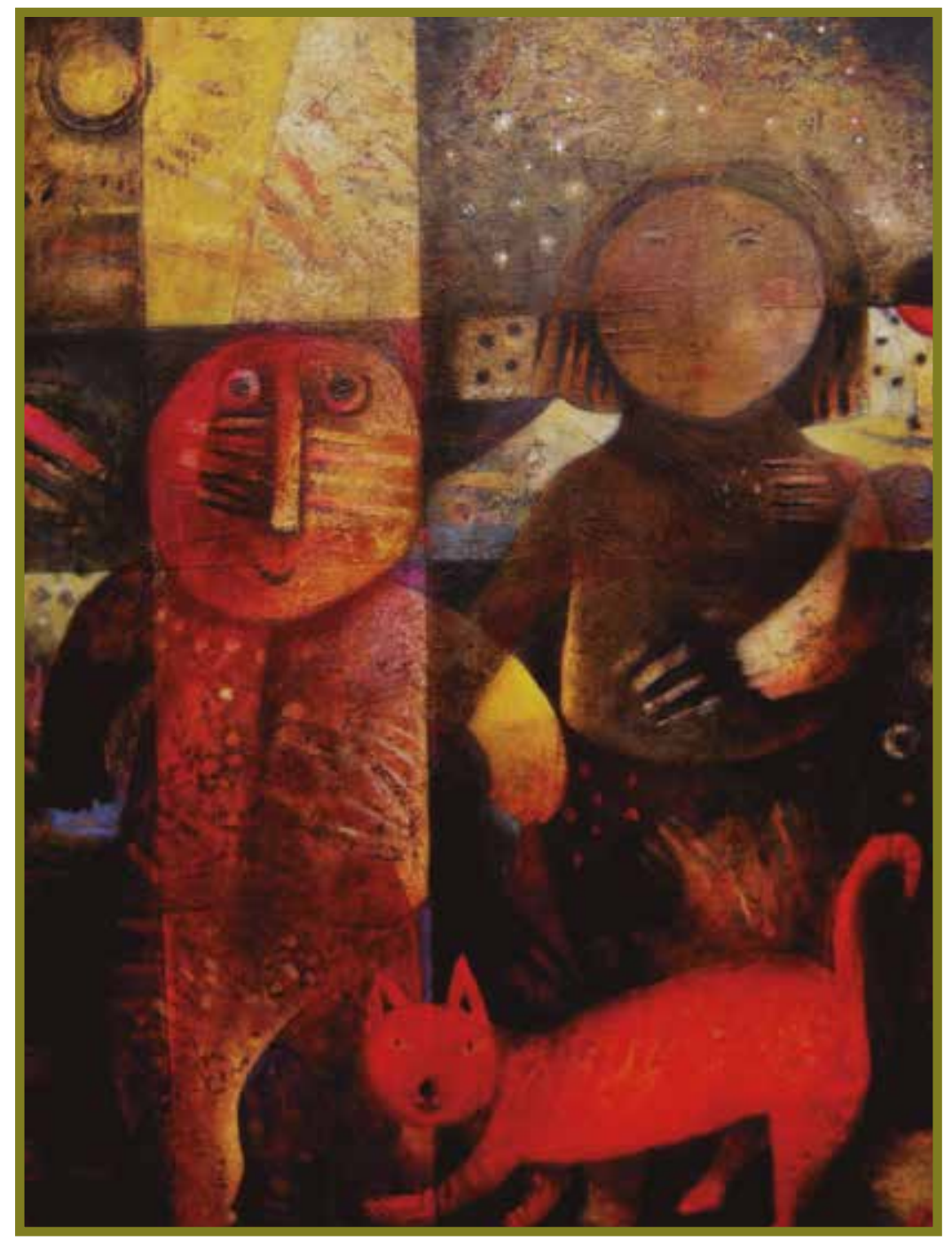

Sombras de la noche. Pintura. Juan Carlos Nananake. 


\section{RESUMEN}

El presente artículo está enmarcado en el estudio de los bienes funerarios con el fin de redimensionar los mecanismos de publicidad de que están dotados los mismos, teniendo como máxima representación de aquella, la creación de una sección dentro del Registro de la Propiedad, que se encargue de brindar una protección eficaz, cautelosa y rigurosa de dichos títulos, bajo la observancia de los principios generales del derecho.

Palabras clave: bienes funerarios, publicidad registral, seguridad jurídica, sección, registro de la propiedad.

\section{ABSTRACT}

This essay is framed in the study of the funerary goods with the purpose of evaluating its mechanisms of publicity, having as its top representation, the creation of a section in the Property Registry to be in charge of providing an effective, prudent and strict protection of such titles observing the general principles of law.

Key words: funerary goods, registries' publicity, legal certainty, section, property registry. 
Las necrópolis son algo más que espacios donde se guardan la tristeza y la nostalgia, es decir, los afectos solemnes que se fijan en pequeñas residencias de mármol o granito; son auténticos museos a cielo abierto, dignos de ser protegidos por sus valores patrimoniales. La Ciudad del Reposo. Cementerio San Rafael, obra inscrita dentro de ese sentido de rescate, es una alerta sobre las cualidades creativas hechas desde la escultura y los quehaceres arquitectónicos, la historia y a entidad cultural que poseen estas instituciones públicas.

Rissell Parra Fontanilles

\section{A MODO DE INTRODUCCIÓN}

La muerte es un tema universal que involucra paradójicamente muchos aspectos de la vida cotidiana y su significado ha sido una preocupación constante en todas las culturas. En algunas, incluso, la condición del ser después de la muerte se ha considerado más importante que la vida en este mundo. De cualquier manera, el hombre ha querido perpetuar la memoria de sus seres queridos por medio de diferentes ritos, ceremonias luctuosas, así como con la creación de hermosos bienes funerarios que integran los patrimonios de las personas naturales y jurídicas, en los diversos espacios de conmemoración, los cuales han dependido de los fenómenos religiosos, económicos, sociales y políticos, en el tracto histórico de la sociedad.

De ahí que los patrimonios funerarios constituyan una construcción colectiva y los cementerios ${ }^{1}$ un espacio privilegiado de la memoria en permanente transformación y recreación de

1 Un cementerio es un lugar en el cual se entierran cuerpos muertos y restos incinerados. El término cementerio proviene del término griego koimetérion, que significa dormitorio o lugar para dormir, porque según la creencia cristiana, en el cementerio, los cuerpos dormían hasta el día de la resurrección, que implica que el terreno está designado específicamente como terreno para enterrar. 
los sentidos que superan concepciones de conservación y tradiciones que los conciben como conjuntos estáticos. Estos a su vez se constituyen en acervos significativos de legados culturales, históricos, artísticos, artesanales, científicos, paisajísticos, arquitectónicos, simbólicos y de tradiciones, usos y costumbres de una comunidad viva con sus muertos. Es decir, son espacios que contienen bienes materiales ${ }^{2}$ que llevan intrínsecos valores inmateriales, vinculados con la cultura, las costumbres y las tradiciones. Por tanto, los cementerios, los monumentos y las costumbres funerarias son testimonios invaluables que representan importantes fuentes de conocimiento acerca del pasado de las diferentes civilizaciones.

Ahora bien, si partimos de considerar la parquedad actual de la legislación en materia funeraria, se vuelve imperiosa la necesidad de una transparente conceptualización de bienes funerarios, sus características, clasificación y a qué naturaleza jurídica responden, pues surge dilucidar el mecanismo de protección más eficiente y eficaz para salvaguardar los títulos de propiedad que existen evitando su deterioro, extravío, comercialización ilegal, entre otros.

El tema del patrimonio funerario o de los bienes funerarios ha sido objeto de numerosas investigaciones en el ámbito internacional, en las ciencias sociológicas y de la historia del arte. ${ }^{3}$ En lo que respecta a estudios sobre patrimonios funerarios, las investigaciones científicas en el país exhiben carencias desde el punto de vista jurídico, se refieren en lo fundamental desde aristas sociológicas, de estudios socioculturales y de la historia del arte, estrechamente vinculadas a temas como el papel fundamental que ha tenido el arte en el acto de escudriñar los signos sociales, sus arquitecturas y urbanismo, regulando así la materialización de los planos que controlan el espacio geográfico, divisiones y subdivisiones del terreno ${ }^{4}$ donde están ubicados estos bienes funerarios; sin que superen las expectativas de la academia y la doctrina patria desde la perspectiva del propio derecho. Esas investigaciones desde la perspectiva jurídica, por lo general, versan sobre la protección del patrimonio funerario, como

2 Cfr. artículo 46.2 del Código Civil Cubano 1987: "Los bienes materiales pueden ser muebles o inmuebles: son inmuebles la tierra, los demás bienes incorporados a ella y los que se unen de una manera permanente a los antes referidos para su explotación o utilización. Son bienes muebles todos los demás".

3 V.gr. en el ámbito internacional: "Breve historia de los cementerios", acceso el 25 de diciembre de 2015, http://cultopia. es/breve-historia-de-los-cementerios-ii/; Francisco Javier Rodríguez Barberán, Los cementerios en la Sevilla contemporánea. Análisis histórico y artístico (1800-1950) (Sevilla: Diputación Provincial de Sevilla, 1996); Philippe Aries, El hombre ante la muerte (Madrid: Taurus, 1984); A. Gonzales Díaz, "El cementerio español de los ss. XVIII y XIX", Archivo Español de Arte, n. ${ }^{\circ} 171$ (1970); Dora Nicolás Gómez, "La tratadística sobre botánica funeraria y el arbolado en los cementerios de Murcia en el s. XIX: a propósito de dos dibujos arquitectónicos en el Museo de Bellas Artes", Revista Verdolay, n. ${ }^{\circ}$ 3 (1991); C. Saguar, "El cementerio del este de Barcelona", Revista Goya, n. 214 (1990); Miguel Ángel Cuenya, "Los espacios de la muerte. De panteones, camposantos y cementerios en la ciudad de Puebla. De la Colonia a la Revolución", acceso el 19 de enero de 2016, https://nuevomundo.revues.org/15202

$4 \quad$ V.gr. la distribución de las calles, aceras, pasillos, linderos, jardines y otras disposiciones físicas de las estructuras cementeriales o luctuosas donde se encuentran ubicados estos bienes; Javier Rodríguez Barberán y Alberto González Díaz, María Elena Cobas Cobiella, Américo Atilio, Cornejo, Ramón de la Rica Arenal, Roca Sastre, La cruz Verdejo, D. Sanz Fernández, Gerónimo Gonzales, Mariano Hermida Linares. 
bien jurídico a salvaguardar desde el punto de vista del derecho penal, con el objetivo de incluir un título en la normativa sustantiva penal encaminado a su protección. Existen otras en el ordenamiento jurídico cubano insertas en el campo del derecho administrativo y civil referidas en lo fundamental a la trasmisión por compraventa de los bienes funerarios en Cuba y la construcción de presupuestos teóricos aplicables a las normas jurídicas que regulen la propiedad cementerial. ${ }^{5}$

La inexistencia de un Registro o al menos de una Sección en el Registro de la Propiedad Inmobiliaria donde puedan inscribirse los bienes de esta naturaleza y con ello se otorgue seguridad jurídica en el tráfico externo, esto es, efectos erga omnes; y la no definición de la normativa vigente de los bienes funerarios, y tampoco su clasificación en atención a su naturaleza jurídica; son las razones que motivaron la presente investigación, que implementa a partir de un análisis doctrinal, histórico y exegético pautas teóricas dirigidas a la de creación de una sección en el Registro de la Propiedad, para la inscripción de los derechos reales sobre los bienes funerarios, así como la elaboración de una Ley Cementerial que elimine la dispersión legislativa y facilite con ello el actuar de los operadores jurídicos.

\section{NOTICIA HISTÓRICA DE LOS BIENES CEMENTERIALES}

Disímiles han sido las formas, prácticas, ritos, ceremonias y lugares utilizados por los seres humanos a lo largo de la historia para que descansen los restos inmortales de aquellos que ya no se encuentran físicamente presentes. Esto por supuesto responde indiscutiblemente a la cultura, tradición y contexto histórico en que nuestras sociedades se han desenvuelto y manifestado, lo que ha llamado la atención de otras ciencias como la arquitectura, la sociología, la antropología, la historia, el derecho y otras. En cierto modo las instituciones cementeriales son muy antiguas. Válido si realizamos un recorrido por las distintas etapas históricas de la humanidad desde la Antigüedad, Edad Media, Moderna y la Época Contemporánea.

En tal sentido se puede augurar que los prístinos antecedentes de esta institución se remontan o datan de la existencia de la vida misma, si bien es sabido el nacimiento y la muerte son dos hechos naturales dentro del proceso evolutivo. La muerte trae consigo la desaparición

5 En la arista nacional se han pronunciado sobre el tema autores como Caridad García Rondón, "La protección jurídico-penal de los cementerios en Cuba" (tesis presentada en opción al grado académico de MS.c en Derecho Penal, Universidad de Matanzas, 2006); Marta Fernández Martínez, profesora de Derechos sobre Bienes de la Universidad de la Habana, vid. artículo publicado en la Revista Cubana de Derecho, 2013, "Titulación efectiva, publicidad inmobiliaria y trasmisión por compraventa de los bienes funerarios en Cuba. Especial referencia a la Necrópolis de Colón”; Arisyennis Yakelín Easy Porro, "El objeto de la propiedad estatal y dominio público del Estado en el derecho cubano" (tesis presentada en opción al título académico de licenciada en Derecho, Camagüey, 2009); Maydelis Ferraz Espinosa, "Insuficiencias de la propiedad cementerial en Cuba: apremiante necesidad de reglamentación” (tesis presentada en opción al título académico de licenciada en Derecho, Las Tunas, 2014), entre otros. 
física de la persona, lo que no implica el olvido de esta por sus seres queridos. Existen entonces por ello los cementerios, ${ }^{6}$ constituidos como un lugar de perpetua memoria. ${ }^{7}$

Ahora bien, en los albores de la civilización encontramos que en la Antigüedad los faraones y reyes del Antiguo Egipto desempeñaron un rol primordial en la religión egipcia, fundamentalmente en la práctica de entierros. $V$. gr., los primeros entierros conocidos de los reyes egipcios provienen del período predinástico, que duró desde alrededor del año 6000 hasta el 3100 antes de Cristo (a. C). Durante este período, los faraones y los nobles fueron enterrados bajo tumbas de adobe denominadas mastabas, es decir, eran de techo plano y tenían los lados inclinados, donde las cámaras funerarias subterráneas estaban cercadas con piedras o ladrillos sosteniendo el cuerpo del difunto bajo la mastaba. Estas cámaras eran propiedad de los reyes y faraones.

Con independencia de lo antes expuesto podemos decir que la mayoría de los cementerios se destinaban a cadáveres humanos, pero también desde la Antigüedad, existían necrópolis para ciertos animales, como el Serapeum de Saqqara en Egipto, conocido además como la primera pirámide-tumba escalonada de Saqqara, al noroeste de la ciudad de Memphis. Las pirámides se hicieron más comunes y de mayor tamaño durante el Imperio Antiguo, que culminó en la Gran Pirámide de Keops, que forma parte del enorme complejo de Necrópolis de Giza. ${ }^{8}$ En Grecia existieron necrópolis que estaban situabas fuera de las ciudades, pero no lejos, en lugares de paso, a lo largo de las carreteras, evitando el olvido de los antepasados y propiciando, a la vez, la seguridad de estos espacios sagrados. Esta cierta lejanía evitaba el riesgo de contagio de enfermedades que podían emanar de estos lugares infectos. En la antigua Mesopotamia, la muerte fue vista como algo negativo, todo giraba en la inexistencia de cualquier forma de vida después de la muerte; por ello el enterramiento era la forma más común para ayudar a las almas a ir al más allá. Normalmente se realizaba cerca o debajo de la casa donde vivían los familiares, aunque en algunas ocasiones se podían ver necrópolis en las afueras de las ciudades. En la antigua Roma, los muertos eran enterrados en sus propias casas: prius in domo sua quisque sepeliebaiur, lo que trajo como consecuencia que se dictaran normas prohibitorias de este uso que ponía en peligro la salud de los seres vivos a causa de la infección de los cadáveres. V. gr., la Ley de las Doce Tablas, norma que extendió aún más las precauciones, prohibía enterrar o quemar cadáver alguno en el recinto de Roma. ${ }^{9}$ Esta prohibición fue

6 Un cementerio, camposanto o panteón es el lugar donde se depositan los restos mortales o cadáveres (inhumación). Dependiendo de la cultura del lugar, los cuerpos pueden introducirse en ataúdes, féretros o sarcófagos, o simplemente envolverse en telas, para poder ser enterrados bajo tierra o depositados en nichos, mausoleos, criptas u otro tipo de sepulturas. A los cementerios católicos se les llama también camposantos, dado que en Pisa, cuando, ateniéndose a medidas de higiene, la autoridad ordenó cerrar el cementerio que había sido construido en el siglo XIII dentro de la ciudad, el terreno fue cubierto con una gran capa de tierra, que las galeras pisanas habían traído de los lugares santos de Jerusalén.

7 Tomado de la tesis presentada en opción al título académico de licenciada en Derecho Maydelis Ferraz Espinosa.

8 La Gran Pirámide data de alrededor de 2560 a. C y es la pirámide más grande conocida. Las pirámides contenían las cámaras funerarias de los reyes y estaban rodeadas de templos funerarios.

9 Estos hipogeos se polarizaban en torno a tumbas de santos o mártires, de ahí nombres como la catacumba de san Calixto 
varias veces renovada así en tiempo de la República como en tiempo de los emperadores. Por algunos edictos de Adriano y de Diocleciano se infiere que las ideas religiosas excluían de las ciudades a los muertos: ne funestentur sacra civitatis. Desde entonces, las tumbas de los romanos se abrieron indistintamente ora en el campo, ora en un jardín de pertenencia del difunto, ora en un terreno comprado al intento. La voluntad de los particulares o de su familia, de sus amigos o de sus patronos era, pues, la que fijaba el lugar de las sepulturas. Los individuos de la hez del pueblo y los esclavos, cuando morían eran echados a una especie de muladares llamados puticuli o culirue.

En tal sentido, si algún patrono u amo generoso quería honrar la memoria de un cliente o de un esclavo fiel y virtuoso, le compraba un terreno para elegirle una tumba o le daba lugar en la sepultura que tenía comprada para sí y para su familia. En las inscripciones sepulcrales se encuentra a menudo esta fórmula: Libertis libertabusque posterisque eorutn. Pero en todos los casos aquellas sepulturas quedaban perpetuamente de propiedad particular, y este derecho se hallaba garantizado por una disposición de la ley de las Doce Tablas, citada por Cicerón: Fori bustive Aeterna auctoritas esto.

Siguiendo el curso de la historia, en la Edad Media se realizan nuevas construcciones para los rituales de sepulturas. $V$. $g r$. se localizaban cercanos a conventos, junto a los muros de catedrales y monasterios esperando con ello una garantía de salvación. En todos los casos aquellas sepulturas quedaban perpetuamente en propiedad particular, y este derecho se hallaba garantizado por una disposición de la ya descrita Ley de las Doce Tablas. Los muertos ahora presentes en la vida cotidiana de los vivos dejaban explícita su diferencia, su jerarquía. La ciudad se convierte en un gran cementerio a pesar de la oposición de las máximas autoridades eclesiásticas. Desde los Padres de la Iglesia hasta los Concilios censuraron enérgica y constantemente los enterramientos urbanos. ${ }^{10}$ Desde el arcaísmo pasando por la Edad Media el crecimiento demográfico y por tanto de cadáveres se agudiza, por lo cual los cementerios en el modernismo, al amparo de la Reforma católica y con una sociedad desvinculada sentimentalmente de sus restos ancestrales, se inician las ampliaciones de iglesias de un modo generalizado en toda Europa debido a que los nuevos postulados eclesiásticos necesitaban de instalaciones específicas para desarrollar sus labores pastorales. $V . g r$., las capillas de comunión, adyacentes a los templos y fruto de una nueva devoción, tomaron en muchas ocasiones terreno de los olvidados cementerios "ad sanctos". Los cementerios, entonces, se ven relegados a lugares apartados, como sucede en el caso francés donde aparecen los primeros cementerios modernos, no adyacentes a las iglesias. La segunda generación de estos nuevos cementerios

o de los santos Pedro y Marcelino.

10 Pío Antonio prohibió enterramientos en las ciudades de todo el Imperio, ley que secundó Diocleciano, Maximiano y Teodosio. Carlos Saguar Quer, "Carlos III y el restablecimiento de los cementerios fuera del poblado", Fragmentos, n. ${ }^{\circ}$ 12-13-14 (1988):182. 
modernos, en el siglo XVIII, se caracterizará por su aislamiento de la población. La mayoría de los antiguos cementerios parroquiales se convirtieron en plazas, mercados o en instalaciones eclesiásticas como capillas, sacristías antes inexistentes, salas para el catecismo, escuelas, entre otros.

Con independencia de lo antes manifestado, en la época contemporánea a partir del siglo XIX, la mayoría de los antiguos cementerios parroquiales europeos se convirtieron en plazas, mercados o en instalaciones eclesiásticas, surgiendo así la segunda generación de nuevos cementerios modernos que se caracterizarán por su aislamiento de la población. ${ }^{11}$ En este siglo es cuando el cementerio cobra identidad propia, confundido con las dependencias de la iglesia. Nacen junto a una serie de reformas urbanísticas que configurarán la ciudad moderna como son el nuevo Ayuntamiento y el Palacio de Justicia, los mercados públicos, la estación de ferrocarril o el teatro, elementos todos ellos de la vida urbana burguesa. Se opera junto con su aparición un cambio de mentalidad; ahora ya no se trata de estar cerca de los difuntos para cuidar sus restos, sino de conservarlos de forma ordenada en un lugar moderno e higiénico y dotarlos de una morada eterna, lo más digna posible. Es entonces cuando se hace evidente una jerarquía social, reproduciendo las mismas actitudes de antańo, pero valiéndose de otros elementos, los panteones y mausoleos que pronto aparecerán hermoseando y dignificando los camposantos. En esta época se observa la costumbre de incorporar el dibujo, como telón de fondo para la arquitectura, arbolado y vegetación. Al parecer la presencia de dibujos y vegetación en los cementerios, tan común y aceptada en el siglo XIX, tuvo sus detractores en el siglo XVIII. Sin embargo, en el siglo XIX la tendencia será completamente contraria. Al amparo del naturalismo romántico, los cementerios se convirtieron en una especie de parque-jardín donde se unen en perfecta armonía vida y muerte, naturaleza y enterramientos, ambos ahora admirados y no rechazados. El cementerio se convertirá en un lugar de paseo donde sus calles y avenidas se asemejan a las alamedas y parques de las ciudades, así como las tumbas a los monumentos conmemorativos de esta misma, donde los ricos y pobres son tratados por igual.

Evidentemente las concepciones y tipologías de los cementerios fueron posteriormente expandidas al mundo entero, adoptando las diversas tendencias modernas que sobre su constitución hoy existen y cuyo tratamiento, aunque interesante, podría alejarnos de nuestro objetivo en este trabajo referente a la existencia de un sistema registral que proteja a los titulares y poseedores de bienes funerarios en nuestro país; es por ello que consideramos prudente hacer una pausa en este recorrido histórico, y destacar algunos apuntes doctrinales de la institución objeto de estudio.

11 En Inglaterra, el cementerio de Rosario en Norwich abrió sus puertas en 1819 como un cementerio interdenominacional. La mayoría de los primeros cementerios, incluyendo Chorlton Cementerio Fila creada en 1821 y baja Hill Cemetery en 1825 , fueron establecidos por conformistas y se encontraban en los centros urbanos con poblaciones en rápido crecimiento. Se establecieron seis grandes cementerios de Londres, incluyendo Kensal Green en 1833 y High Gate en 1839. 


\section{APUNTES TEÓRICOS DE LOS BIENES FUNERARIOS}

Se ha aludido a que la relación existente entre los particulares y el Estado puede ser la de un Usufructo, una Servidumbre, un Derecho de Uso o Habitación, una Propiedad Horizontal, una Copropiedad y finalmente las más controvertidas en la actualidad, ${ }^{12}$ las de una Concesión Administrativa, un Derecho de Propiedad o un Derecho Perpetuo de Superficie. El usufructo consiste en un derecho temporario, siendo el plazo máximo de duración el de la vida del usufructuario y resultando intransmisible a los herederos y por actos intervivos. El usufructuario tiene la facultad de ceder el ejercicio de su derecho, a título gratuito u oneroso, resultando el derecho mismo inaccesible, por cuanto ante la muerte del usufructuario, cesa el usufructo y las facultades del cesionario. Estas consideraciones llevan a excluir la posibilidad de configurar el derecho al sepulcro como un usufructo, ya que el titular de la sepultura tendría en vida el uso y goce de la cosa, pero estas facultades se extinguirían a su muerte, que es cuando en realidad necesita hacer uso de su derecho.

Por ser la servidumbre ${ }^{13}$ un derecho perpetuo o temporario sobre un inmueble ajeno, en virtud del cual se puede usar de él o ejercer ciertos derechos de disposición o bien impedir que el propietario ejerza algunos de sus derechos de propiedad, nos resulta difícil admitir esta figura para configurar un derecho real de esta naturaleza en esta sede. En cuanto al Derecho de Uso y Habitación, este instituto ha sido ampliamente utilizado en Perú, ${ }^{14}$ España ${ }^{15}$ y Costa Rica, ${ }^{16}$ por mencionar algunos. Se considera que la adopción del derecho real de uso para regir las relaciones de los particulares no se adecua, pues hacen referencia a la constitución de un derecho real de uso a perpetuidad, lo que desnaturaliza por completo tanto al derecho real en sí mismo como a los bienes cementeriales, cuya naturaleza jurídica resulta de orden público en cuanto a los terrenos expropiados. En lo que respecta al Derecho Real de Habitación, este es inadmisible por el hecho de que se configura sobre una finca, dando la facultad de morada

12 Antes de la nacionalización quedó claro que el régimen jurídico era el de un verdadero Derecho de Propiedad.

13 Vistas como limitaciones de interés público, las llamadas servidumbres administrativas por Orlando Rivero Valdés, Temas de derechos reales (La Habana: Ed. Félix Varela, 2005), 76.

14 Ley No. 26298 de 22 de marzo de 1994 "Ley de Cementerios y Servicios Funerarios" de la República de Perú, en su artículo 7 dispone que los cementerios son públicos o privado. A su vez, las sepulturas son bienes sui géneris que otorgan un derecho de uso (o quizás usufructo) temporal o perpetuo, siendo además inembargables.

15 El uso privativo por los particulares de terrenos del cementerio se rige por las normas del Reglamento de Bienes, Actividades, Servicios y Obras de las entidades locales de Aragón y por el Reglamento de Bienes de las Entidades Locales de 1986. El artículo 93.3 de la Ley 33/2003, de 3 de noviembre de 2003, del Patrimonio de las Administraciones Públicas, referido a las concesiones demaniales, establece que "Las concesiones se otorgarán por tiempo determinado. Su plazo máximo de duración, incluidas las prórrogas, no podrá exceder de 75 años, salvo que se establezca otro menor en las normas especiales que sean de aplicación”. Este artículo 93.3, según la Disposición Final Segunda de la propia ley, tiene carácter de la legislación básica, de acuerdo con lo preceptuado en el artículo 149.1.18. a de la Constitución española.

16 Decreto-Ley N 704 de 7 de septiembre de 1949 "Regulación sobre Propiedad y Arrendamiento de Tumbas en Cementerios", en su artículo 1 refiere que los derechos de la propiedad o arrendamiento sobre las parcelas, tumbas, mausoleos y demás sitios en los cementerios, solo podrán ser traspasados a terceras personas cuando no hayan sido usados, o cuando habiendo sido usados, se hubieren exhumado todos los restos que ellos contengan. 
en ella al habitador y su familia, por lo que resulta absolutamente incompatible con la figura que nos ocupa, al no ser su fin el de morada en vida sino luego de producirse el deceso.

En otro orden, el debate se ha dirigido hacia su posible configuración como un Derecho de Propiedad Horizontal, o Propiedad por Pisos, la que por definición propia se constituye exclusivamente sobre edificios divididos por pisos, locales, susceptibles de aprovechamiento independiente. Este derecho atribuye al titular de cada una de las titulares individualizadas que la integran, un derecho singular y exclusivo sobre los mismos, así como un derecho de copropiedad conjunto e inseparable sobre los restantes elementos, pertenencias y servicios comunes de inmueble. De la sola enumeración de los requisitos, para afectar un inmueble al régimen de la propiedad horizontal deriva la imposibilidad de su asimilación al Cementerio de Colón. Resulta inapropiada también la figura del condominio, el que tendría lugar entre el propietario del cementerio (Estado) y los particulares. Como parte de los derechos que engendran, los condóminos podrían siempre y en cualquier momento solicitar la división y consecuente partición del predio, destruyendo así el sistema de unidad cementerial. Descartadas estas posibles tesis, veamos las que a pesar de ser las más atinadas resultan de igual manera polémica. Un primer punto a tener en cuenta es la inexistencia, hasta el momento, de cementerios privados en el país, práctica que contrario sensu está teniendo lugar en otros países de la región, América Latina y Europa. De ello resulta que los cementerios se consideran bienes pertenecientes al dominio público, al tratarse de obras públicas construidas para utilidad o comodidad común. ${ }^{17}$ Estos bienes funerarios se encuentran dentro de un enramado legal en el que intervienen elementos contractuales, administrativos e inmobiliarios o de derechos reales, que hacen este régimen aún más complejo e indeterminado.

Un segundo punto a tener en cuenta, es que aun y cuando el Reglamento de 1948, vigente hasta 1995, pretendía establecer un régimen jurídico único, en la práctica trajo determinados problemas que hoy resultan de difícil solución, porque hemos logrado constatar y defender que las concesiones otorgadas como derechos de propiedad, o al menos, así se dispuso aún y cuando el Estado se estableció como propietario del lugar pero con las particularidades antes descritas, pues respetó las propiedades que allí existían a nombre de los titulares de las mismas, nos hacen pensar y de hecho así se comporta en relaciones de orden privado, pero luego, la vía de escape que resultaron ser los documentos de uso emitidos por la Administración, toman otro rumbo, como posibles concesiones administrativas, ${ }^{18}$ respondiendo a relaciones,

17 En el caso del Cementerio de Colón, hágase la salvedad de la existencia de los derechos de propiedad sobre los bienes funerarios expedidos por la Administración luego de la nacionalización, ya que el objetivo fundamental de esta, y es importante recalcarlo, no fue expropiar a los titulares de sus propiedades cementeriales, sino retirarlas de una vez y por todas a la Iglesia, pues con esta última no cumplía con un verdadero fin socializador.

18 También es cuestionable aceptar esta tesis por el hecho de que no son inscribibles dichas concesiones administrativas, según la doctrina, en ningún Libro de Concesiones, tal como sí ocurre en nuestra realidad material, aunque no otorga ninguna seguridad a los particulares. Otro motivo para descartar esta posibilidad es que la concesión administrativa, y en 
esta vez de orden público, ${ }^{19}$ visto que se utilizaron para acreditar, como ya habíamos señalado, la posesión, tenencia o utilización para enterramientos de determinadas personas que no eran propietarias de ningún bien funerario y que querían proceder a enterrar honrosamente a sus finados. Esto es así porque en efecto, una vez otorgado estos documentos de uso, por un tiempo indeterminado, se sobreentendía que estos eran del Estado, concedidos para un fin específico y que no podían ser por parte de los sujetos a quienes le eran entregados, embargados, enajenados o prescriptibles. Resulta curioso que en la actualidad todo ello se pueda realizar sin que se tomen las medidas necesarias para evitar los fraudes que se están cometiendo con estos documentos que en definitiva no son verdaderos títulos de propiedad, aun cuando los sujetos pretendan que se comporten como aquellos por motivos de índole económica.

Después de lo expuesto a priori, considero que la fuente donde radica el problema ${ }^{20}$ central y el núcleo duro a resolver para todos los estudiosos que deciden iniciar sus investigaciones en este campo, califico que lo más apropiado resultaría el establecimiento de un derecho real ya configurado en nuestro Código Civil, ${ }^{21}$ que armoniosamente resuelve varias cuestiones, a saber, en primer lugar, el mantenimiento de la propiedad de los terrenos y bienes cementeriales construidos bajo la titularidad del Estado, representada por la Dirección Provincial de Servicios Comunales con su dirección y gobierno en manos del Consejo de la Administración de las provincias, en pos de garantizar la función social para lo que fuera nacionalizada la Necrópolis, evitando cualquier tipo de especulación o abuso de los mismos; en segundo lugar, los particulares, se beneficiarían, ya que tendrían un derecho perpetuo si bien no sobre el suelo, sí sobre lo construido o lo que construyan en el plazo legal que estipulen las normas, transmisible perfectamente a los herederos del titular una vez fallecido, mortis-causa o en vida por los actos intervivos destinados a este fin estipulados en el Código Civil cubano. ${ }^{22}$

esto es mayoritario el pronunciamiento de la doctrina administrativista, se caracteriza esencialmente por ser un contrato administrativo que crea un derecho real administrativo; sin embargo, la naturaleza aparente de los Documentos de Uso son precisamente eso, autorizaciones para usar, últimamente entregadas por un plazo de tiempo limitado por 5 años y no ninguna suerte de contratos, con las características propias de estos, estudiadas en Derecho de Contratos y Derecho Administrativo. Las concesiones administrativas como régimen que intenta describir la propiedad cementerial, aun salvando las peculiaridades que debería tener en este ámbito, no se asemejan con la generalidad a la que responde el régimen de las concesiones administrativas mineras, concesiones administrativas derivadas del régimen de inversión extranjera, etcétera.

19 La nebulosa existente en cuanto al régimen establecido también parte de quienes han afirmado que no es un derecho real de derecho civil lo existente, sino un derecho administrativo configurado a la manera de un derecho real del derecho civil, con lo que no concuerdo plenamente.

20 La jurisprudencia del Tribunal Supremo Argentino ha sostenido que la propiedad sobre las sepulturas es especial y sui géneris y que en la regulación del derecho funerario conviven derecho privado y disposiciones de derecho público de difícil interrelación.

21 Independientemente de que puedan adquirirse dichos bienes funerarios por las formas establecidas en el Código Civil cubano, tal como lo propone el Anteproyecto de Decreto- Ley Cementerial que esperemos, para salvaguardar el principio de legalidad socialista, vea la luz finalmente este o el próximo año.

22 Cfr. artículo 178 del Código Civil de la República de Cuba: La propiedad y demás derechos sobre bienes se adquieren y trasmiten por la ley, los acontecimientos naturales, los actos jurídicos, la accesión y la usucapión. La transmisión se consuma mediante la entrega o posesión. 
Por último logaríamos la configuración de un estricto sistema registral que inscribiese el derecho otorgado por la Administración, actualizando toda la información existente hoy en los archivos de los camposantos, dando inicio a una nueva etapa en la historia de la propiedad cementerial en Cuba.

Sin dudas, en el párrafo que nos antecedió estamos refiriéndonos a la figura del Derecho Perpetuo de Superficie, siempre que se adapte a este fin ya que si partimos de su definición como: "el derecho real mediante el cual un sujeto (superficiante) (Estado) concede a otro (superficiario) (particular) el derecho a construir o mantener lo construido, sobre el suelo de su propiedad, con carácter perpetuo o temporal, deviniendo el superficiario propietario de lo construido, con independencia de la propiedad del suelo", ${ }^{23}$ se corresponde de manera pertinente con las propuestas inicialmente planteadas y daría solución a una parte del problema de nuestra investigación por los inconvenientes formulados a raíz del actual régimen jurídico.

Hoy se torna difícil, en ausencia de un Registro de Propiedad de Bienes Funerarios, contabilizar y mantener las estadísticas exactas acerca de la cantidad de bienes que se encuentran presentes en los cementerios del país. La certeza de los sujetos que dicen ser los verdaderos titulares domínicos de los bienes funerarios, ya sean personas naturales, las organizaciones o el Estado, no puede corroborarse y está sujeto, por tanto, constantemente a cuestionamientos, pues el sistema publicitario es resultado de procedimientos meramente formales, los cuales no están sometidos a reglas estrictas a pesar de la connotación que tiene para el Derecho Real y los particulares la inscripción de los bienes inmuebles. En consecuencia, el estudio se limitará a enunciar aquellos que en virtud de su naturaleza misma, existe gran unanimidad entre la doctrina $^{24}$ y las legislaciones ${ }^{25}$ al regularlos como bienes que no deben escapar de esta clasificación, y que someramente resultan los que siguen:

Bóvedas: Excavaciones con una capacidad de enterramiento de más de dos ataúdes, cuyas paredes se forran de ladrillos o bloques levantadas sobre el nivel del suelo a unos setenta u ochenta metros, revestidas de mármol u otro material de $1,10 \mathrm{~m}$ de ancho por 2,40 m de largo, generalmente acompañadas de osarios pues las familias preferían

23 Orlando Rivero Valdés, Temas de derechos reales (La Habana: Ed. Félix Varela, 2005), 122.

24 Vid. Martha Fernández Martínez, "Titulación efectiva, publicidad inmobiliaria y trasmisión por compraventa de los bienes funerarios en Cuba. Especial referencia a la Necrópolis de Colón", 1; Maydelis Ferraz Espinosa, "Insuficiencias de la propiedad cementerial en Cuba: apremiante necesidad de reglamentación" (tesis presentada en opción al título académico de licenciada en Derecho, Las Tunas, 2014).

25 Resolución No. 1477 de 11 de mayo de 2009 del Ministerio de la Protección Social de la República de Colombia, en sus artículos 29 y 30. Ley No. 26298 de 22 de marzo de 1994 "Ley de Cementerios y Servicios Funerarios" de la República de Perú, artículo 6. La Ordenanza General de Cementerios No. 12288 de 4 de diciembre de 1998 para la Municipalidad de Pueyrredon, Espańa, artículo 2. El Decreto No. 320 de 10 de mayo de 1973 de la República del Salvador, artículos 18 y siguientes. 
construirlos de este modo, para que una vez exhumados los restos, quedaran en la demarcación de su propiedad.

> Capillas: Edificaciones funerarias compuestas por bóveda, altar que resalta la función ritual, y osarios. Su característica principal es que son techadas, con puertas y ventanas, como imitando una pequeńa vivienda.

> Criptas: Lugares subterráneos destinados al enterramiento de cadáveres.

> Lápidas: Piedras llanas en que ordinariamente se coloca una inscripción relativa al difunto.

> Mausoleos: ${ }^{26}$ Construcciones de grandes dimensiones, suntuosidad y riquezas decorativas que poseen un carácter conmemorativo, generalmente usados en la actualidad como sitios históricos, donde descansan los restos mortales de las grandes efigies.

$>$ Nichos: Concavidades en el espesor de un muro, para colocar restos humanos.

$>$ Osarios: Excavaciones más pequeñas que se utilizan para la colocación de restos después de las exhumaciones y miden más o menos $1 \mathrm{~m}$ de largo u 0,80 $\mathrm{m}$ de ancho y pueden estar revestidos de material pétreo artificial.

> Panteones: Conjuntos de bóvedas que pueden tener osarios, formando un todo delimitado de varias maneras, constituyendo un único inmueble, que puede ser familiar o social. Algunas presentan espacio para esculturas.

> Sepulcros: Obras, por lo común de piedra, que se construyen levantadas del suelo, para dar en ella sepultura al cadáver de una o más personas, en donde se depositan además las reliquias y que después se cubre y sella.

$>$ Sepulturas o tumbas comunes: Excavaciones efectuadas en tierra para depositar un cadáver, sobre las que se levantan obras de piedra, concebidas en ocasiones como armazones en forma de ataúd destinado para la celebración de las honras del difunto.

$>$ Fosa común o fosa en tierra: Excavación que debe tener como promedio $2 \mathrm{~m}$ de largo por $0,80 \mathrm{~cm}$ de ancho y alrededor de 1,50 m de profundidad. En muchos cementerios del mundo las inhumaciones se efectúan directamente en la tierra; ${ }^{27}$ convirtiéndose esta en un bien cementerial cuando se destina a este fin, y cae bajo su régimen jurídico.

26 Deben su nombre a Mausoleo, Rey de Caria, al que su esposa Artemisa erigió una suntuosa sepultura en Halicarnaso, tras su muerte en el año $353 \mathrm{a}$. C.

27 El estilo de los cementerios es muy variable internacionalmente. En los Estados Unidos y en muchos países europeos, los cementerios modernos tienen muchas lápidas colocadas en espacios abiertos. En Rusia, las lápidas se colocan en pequeños lotes familiares valladas y su adquisición resulta costosa. En Cuba también se practican estas formas de enterramientos, mayormente en cementerios rurales. 
Sin embargo, podemos decir que existen otras clasificaciones en la doctrina sobre estos bienes, otros cuyo fin no resulta colaborar en el enterramiento mismo de las personas, sino que cumplen una función social al ornamentar los reposos eternos. Estos poseen un fuerte trasfondo religioso, místico y artístico, fijados a los lechos mortuorios; influyendo en que algunos alcancen reconocimientos como monumentos nacionales y hasta patrimonios culturales de la humanidad. Dentro de ellos figuran los siguientes: ${ }^{28}$

Estatuas: Obras de escultura labrada a imitación del natural, con un alto sentido religioso, concebidas como adorno incorporado al conjunto funerario, para ponderar y engrandecer la personalidad de un difunto.

$>$ Floreros: Macetas o tiestos artísticamente adornados, utilizados para colocar flores naturales o artificiales en conmemoración a un difunto. Reconocidos además como cajas destinadas a colocar flores.

$>$ Jardineras: Muebles o instalaciones fijas para poner plantas de adorno directamente en la tierra o en macetas junto a la sepultura del difunto.

$>$ Monumentos: Obras públicas y patentes, compuestas por estatuas, monolitos u obeliscos, incorporadas a sepulcros en memoria de los difuntos por su mérito excepcional, que poseen valor artístico, arqueológico o histórico.

> Urnas: Receptáculos en el que se conservan imágenes religiosas, fotografías, floreros y otros objetos en conmemoración al difunto.

$>$ Epitafios y esculturas: Elementos fijados a los lechos mortuorios que presentan un fin ornamental, con marcado carácter religioso en su mayoría y con un valor artístico indiscutible.

\section{ACTUALIDAD JURÍDICO-PRÁCTICA DE LOS BIENES CEMENTERIALES EN CUBA}

Analicemos entonces el actual sistema publicitario cubano en sede de bienes funerarios, sus deficiencias, sus aciertos, la necesidad del perfeccionamiento de las instituciones encargadas de dar seguimiento y mantenimiento a los Libros de Concesiones, ${ }^{29}$ que no se encuentran en todos los cementerios del país. Actualmente se espera que los documentos expedidos por los cementerios hagan referencia al lugar en que se encuentra el bien, el acto jurídico por el

28 Cfr. los trabajos realizados por estas autoras, donde refieren dichas clasificaciones: Maydelis Ferraz Espinosa, "Insuficiencias de la propiedad cementerial en Cuba: apremiante necesidad de reglamentación”; Martha Fernández Martínez, "Titulación efectiva, publicidad inmobiliaria y trasmisión por compraventa de los bienes funerarios en Cuba. Especial referencia a la Necrópolis de Colón”, 1.

29 Mediante los llamados Libros de Concesiones es que hace años, en Cuba, especialmente en la Necrópolis citadina de Colón se mantiene un relativo control sobre los bienes funerarios. 
cual se adquirió la propiedad del mismo, con la debida descripción del bien funerario y con el valor estimado en los libros de los cementerios de forma conjunta donde, en la mayoría de los casos, no se corresponde la descripción de los bienes o la ubicación en el soporte papel con la realidad, lo que genera una suerte de caos para los sujetos que necesitan documentos oficiales contentivos de determinada información.

Ahora bien, no podemos dejar de mencionar que el único Reglamento que ha abordado el tema de la publicidad de manera precaria es el de 1948, que se mantuvo vigente hasta 1995, el reglamento del Cementerio Capitalino Cristóbal Colón. Dentro de su contenido configuraba que los particulares tenían "el deber de inscribir las transmisiones en el Registro de Concesiones", figura esta que comienza a regir con este reglamento y que se mantiene hasta la actualidad, regulado por la normativa interna de la Necrópolis capitalina. El Reglamento establece que "En dicho Registro se asentarán el nombre y los apellidos del adquirente de la concesión, la situación exacta y medidas de terrenos objeto de la concesión, sus transferencias domínicas y embargos, nulidad, clausura, expedición de duplicados de títulos y cualesquiera otras circunstancias que afecten a las condiciones de la concesión o al derecho de sus titulares, o cuya anotación sea ordenada por la Administración de la Necrópolis o las autoridades competentes". ${ }^{30}$ Conocidos estos como libros de Protocolo, ${ }^{31}$ en ellos se encuentran registradas todas las concesiones de carácter perpetuo que se llevaron a cabo desde la inauguración del cementerio citado hasta 1962, fecha que parece indicar que se agotaron los terrenos a perpetuidad.

Los libros están conformados por unos modelos de la Dirección Facultativa del sacrosanto lugar, donde brevemente se describe el sitio donde se encuentra el bien, así como el nombre del adquirente, no siendo esto unánime para todos los cementerios de la nación. ${ }^{32}$ Es vital aclarar que el contenido de estos libros no se encuentra en más ningún lugar asentado, ni tan siquiera digitalizado, por el gran volumen de información que se halla en ellos, solo en tarjetas que reúnen los datos más elementales para que trabaje el personal administrativo.

Compartimos el criterio que se sostienen en las investigaciones precedentes sobre la utilización del término Registro, que a consideración de los autores está mal empleado; ya que

30 Vid. Marta Fernández Martínez, "Titulación efectiva, publicidad inmobiliaria y trasmisión por compraventa de los bienes funerarios en Cuba. Especial referencia a la Necrópolis de Colón”, 30.

31 También son conocidos como Libros de Amillaramiento.

32 Los mencionados datos solo se llevan en hojas, quedando un espacio en blanco donde se apuntan las anotaciones pertinentes a los datos ya aludidos en principio con pluma o lápiz informalmente, incluyendo la fecha de la escritura pública por la que se hizo el traspaso o datos de la sentencia firme recaída en proceso ordinario de usucapión, o actos de disposición de clausura de bóveda y segregaciones, y todo lo referente a los bienes. Constatamos, además, que, al finalizar esta hoja, se adicionan otras de cualquier tipo y calidad y se prosiguen las anotaciones. Otro padecimiento es que al no poderse incorporar estas hojas a los libros por imposibilitarlo el antiquísimo encuadernamiento, se adjuntan con presillas o simplemente se sitúan al dorso de la principal, expuestas al peligro de extraviarse o unirse con otras. 
realmente lo que existe son libros de asientos, ${ }^{33}$ que se encuentran expuestos al deterioro, sin más normas de conservación, que las que el personal que trabaja con ellos y sin recoger todos los datos necesarios". ${ }^{34}$ Como bien es sabido inicialmente, cuando los cementerios estaban a cargo de las iglesias, no existía la necesidad de un registro de la propiedad cementerial, pues pese a que la Iglesia era la institución encargada también del Registro del Estado Civil, era sencillo identificar a los propietarios de los bienes funerarios, además de que ya se contaba con un libro de protocolo notarial. Pero con el advenimiento del desarrollo tecnológico, económico, social y político, la administración de los cementerios pasa a manos de las Direcciones Provinciales de Servicios Comunales, organismo que evidentemente no es el encargado actualmente del Registro del Estado Civil como lo ostentaban las iglesias. Seguido de este cambio de administración se inició un censo en la capital del país en 1986, ${ }^{35}$ con vistas a ordenar los documentos y declarar las propiedades existentes en los cementerios, fundamentalmente el de la Necrópolis, otra vía debió haberse concebido, que solucionara, entre otros problemas, el estatus jurídico del 70 u 80 por ciento de las propiedades que se hallan en los cementerios, que no están ni siquiera en manos de los causahabientes.

La falta de un registro ha traído aparejado también el desconocimiento del estado en que se encuentran muchos de los bienes funerarios. Unida a ello, la creación de los llamados documentos de uso, ${ }^{36}$ emitidos solamente por el cementerio capitalino como solución y soporte legal que ha pretendido proteger a los poseedores precarios, hace que se vayan aumentando los problemas, ya que si bien fue una vía rápida de proteger a estas personas, nunca se estableció el plazo de tiempo por el que se otorgaría, ${ }^{37}$ pero además no fue extendido a otros cementerios del país. Teniendo en cuenta la falta de certeza que sufren hoy los títulos de propiedad sobre los bienes funerarios en Cuba, que hemos dejada plasmada en esta investigación como resultado de ese tiempo transcurrido, y circunstancias presentes en las que se encuentra, es que asumimos un serio compromiso, de cara al futuro, que tenga en cuenta un riguroso y

33 No existe una ordenación alfabética de los libros, ni por fincas. Inicialmente no nacieron con la intención de proteger a los ciudadanos y sus derechos reales sobre los bienes, sino que fueron concebidos para satisfacer los intereses de los arquitectos y para tener el control de las importantes obras que se erigían como monumentos y que actualmente se conservan en el cementerio, siendo estas una de las posibles causas subjetivas de las fallas del mecanismo.

34 Marta Fernández Martínez, “Titulación efectiva, publicidad inmobiliaria y trasmisión por compraventa de los bienes funerarios en Cuba. Especial referencia a la Necrópolis de Colón”, 41.

35 El censo iniciado en 1986 y extendido hasta la fecha de 1989, aunque no culminado y por tanto incumplido su objetivo de actualizar el sistema publicitario de la Necrópolis, aportó más de 600 planillas con datos, bien conservados aún, declarados por los sujetos censados sin forma de verificar sus alegaciones, pero que contribuyeron a contabilizar un determinado número de propiedades, que significan un punto de partida importante para un próximo censo.

36 Estos buscaban ser un equivalente a un título de propiedad, aunque no es lo mismo, pues no permiten la facultad de disponer de los bienes a quienes lo ostentan, trajo otros conflictos como los de tener inclusive mayor valor que los títulos de propiedad en determinadas ocasiones.

37 Hace aproximadamente dos años, la administración del Cementerio de Colón decidió limitar temporalmente por un término de 5 ańos los denominados Documentos de Uso, medida que no responde a ningún precepto legal preestablecido, limitando así el derecho de dichos poseedores sin sustrato legal alguno, más que la potestad discrecional de la administración. 
eficiente control sobre dichos documentos, tanto en lo que se refiere a su preservación como a su circulación en el tráfico jurídico. No cabe la menor duda de que tras las informaciones aportadas, es palpable la flexibilidad que opera en la inscripción en los Libros de Protocolo, en todo el sistema en general, las ilegalidades, inseguridades y falta de conocimiento de los procedimientos para trasmitir o adquirir la propiedad de los bienes funerarios, así como la ausencia de rigor en el control de estas, pudiendo resumirse las principales deficiencias de la siguiente forma:

$>$ No existe una disposición única en materia de bienes funerarios en el país que elimine la profusión existente, ni la normativa que conceptualice y clasifique con claridad los mismos.

$>$ Inexistencia de un registro o una sección en el Registro de Bienes Inmuebles referida específicamente a los bienes funerarios, donde se esclarezcan sus estatutos y quiénes son los titulares de estos; por tanto, se obstaculiza con ello el tráfico jurídico, imposibilitando la publicidad registral y debilitando consigo la seguridad jurídica para las personas naturales o jurídicas titulares de estos bienes.

$>$ Solo el cementerio de Colón cuenta con un sistema de publicidad que, aunque imperfecto, es más de lo que en otros existe. Imperfecto pues solo cuenta con un registro administrativo, y por tanto los registros realizados de los bienes no son un Registro de Derecho organizado, correctamente estructurado, como ya habíamos anunciado.

$>$ Se desconocen en todo el país las cifras precisas de la cantidad de propiedades que hay y por quién están siendo usadas.

$>$ Las formas de adquisición y transmisión que rigen actualmente son deficientes pues no están refrendadas en un cuerpo normativo de manera coherente, con las garantías necesarias para que las mismas pueden ser implementadas por quien lo requiera, ni se establecen los procesos judiciales correspondientes ante inconformidad o ilegalidad con los procesos de adquisición o transmisión. ${ }^{38}$

Este es el estado actual en que se encuentra un patrimonio de incalculable valor histórico, arquitectónico y cultural que constituye el fundamento práctico de la imperiosa e impostergable necesidad de dotar de seguridad al mismo, mediante la tan reiterada, y esperemos que por ello alcanzable en el más breve tiempo posible, sección en el Registro de la Propiedad para la inscripción de estos bienes. En este sentido, proponemos determinadas pautas que sirvan de marco a quienes en la práctica, dígase los operadores del derecho, tengan la compleja mi-

38 Limitándose solamente en la mayoría de las provincias a la compraventa y donación de bóvedas y solares yermos ante notario público, a los efectos de construir un bien funerario sin que medie inscripción alguna de estos títulos dominicos, no siendo admisible mediante permuta de bienes funerarios, como ocurre en legislaciones foráneas. 
sión de desarrollar los mecanismos para concebir en los tiempos venideros el objetivo general de esta investigación, logrando que arriben a feliz término sus propuestas de ser coincidentes con la voluntad política y jurídica estatal.

Primero: Llevar a cabo la realización de un censo de calificación que permita actualizar y esclarecer los conceptos en los que los diferentes sujetos de derecho detentan los bienes funerarios, los datos de los mismos y su cuantificación.

Segundo: Crear una sección dentro del Registro de Propiedad de cada provincia, donde exista un profesional del derecho que se encargue de la inscripción, emisión de certificaciones y otros servicios relacionados con los títulos de propiedad, o bien la existencia de un Registro Público en el interior de los cementerios del país en última instancia, a cargo del Ministerio de Justicia y sometido a sus controles y normativa registral vigente, teniendo en cuenta que en otras legislaciones foráneas tienen un registro aparte donde inscriben esos títulos domínicos. En última instancia, que se incluya en el artículo 5 de la Resolución 114/ $07^{39}$ un inciso destinado a inscribir los derechos reales que se constituyan sobre bienes funerarios, apoyándose en las secciones que actualmente existen ${ }^{40}$, en dependencia del lugar donde se encuentre el bien.

Tercero: Incluir de manera taxativa en las normativas de justicia todo el contenido de la actividad registral que se desarrollará, referida a los títulos de propiedad sobre los bienes funerarios, como objeto social.

Cuarto: Que se aplique la misma rigurosidad de los Registros de la Propiedad existente en cada provincia en lo referente a los principios registrales a tener en cuenta, la responsabilidad, calidad del trabajo de los registradores de la propiedad en la inscripción y expedición de certificados, entre otras, atemperándolo a las condiciones materiales de los bienes existentes en el camposanto, ya que estos exceden en buena medida a la cantidad de fincas que pueden existir en un municipio determinado del país.

Quinto: Definir el tipo de publicidad que brindará la sección creada para el sistema publicitario de los bienes funerarios dentro del Registro de la Propiedad. $V$. gr. cuestiones relativas a qué tipo de información tendrá acceso la población y los términos para ello, debido al carácter sacrosanto y religioso que le he impregnado nuestra sociedad a los bienes funerarios, que en ocasiones debe exigir determinada secretividad y requisitos para aquellas personas que deseen acceder a dicha información.

39 Resolución 114/07 sobre "las normas y procedimientos para la organización y funcionamiento del registro de la propiedad".

40 Cfr. artículo 81 de la Resolución 114/07, donde establece que el registro de la propiedad se organiza de forma gradual en dos secciones, una urbana y otra rural. 
Por último, coincidimos con las investigaciones precedentes ${ }^{41}$ en que resulta necesario implementar una Ley Cementerial en Cuba que regule un concepto de bienes funerarios o cementeriales, las modalidades de bienes reconocidas por el ordenamiento jurídico y la doctrina, las características y los principios registrales que servirán de sustento a esta institución a partir de los establecidos en la normativa registral vigente para el Registro de la Propiedad y demás particularidades. Así se pondría fin a la dispersión legislativa existente y a los cuestionamientos doctrinales y jurídicos abordados en esta investigación.

\section{REFLEXIONES FINALES}

Primera: De las similitudes entre ciertas instituciones de la Antigüedad, Edad Media, Moderna y la Época Contemporánea se concreta el surgimiento incipiente de los bienes funerarios desde la Antigüedad. No obstante, el desarrollo de esta institución alcanza un alce vertiginoso en la contemporaneidad cuando las concepciones y tipologías de los cementerios fueron expandidas al mundo entero, adoptando las diversas tendencias modernas que sobre su constitución hoy existen, surgiendo así la denominación de los panteones y mausoleos.

Segunda: Del estudio doctrinal de los bienes cementeriales, referido a su conceptualización, nos percatamos que se discuten algunas posiciones básicas en cuanto a su definición en la academia patria, no siendo así en el ámbito extranjero, debido al poco tratamiento dado a estos bienes a nivel foráneo desde el punto de vista jurídico y teórico. En consecuencia, se admiten varias modalidades de bienes cementeriales, con particularidades adicionadas por cada ordenamiento jurídico interno.

Tercera: Dada la deficiente regulación jurídica de los bienes funerarios en el ordenamiento jurídico cubano, que imposibilita garantizar una seguridad jurídica en el tráfico externo, se hace necesario crear un registro o una sección en el Registro de la Propiedad referida específicamente a los bienes funerarios. En última instancia, que se incluya en el artículo 5 de la Resolución $114 / 07^{42}$ un inciso destinado a inscribir los derechos reales que se constituyan sobre bienes funerarios, apoyándose en las secciones que actualmente existen, ${ }^{43}$ en dependencia del lugar que se encuentre el bien; donde se esclarezcan sus estatutos, quiénes son los titulares de estos, la cantidad de propiedades que hay y si están siendo usadas o no por sus verdaderos

41 Vid. Martha Fernández Martínez, profesora de Derechos sobre Bienes de la Universidad de la Habana, artículo publicado en la revista cubana de derecho, 2013, "Titulación efectiva, publicidad inmobiliaria y trasmisión por compraventa de los bienes funerarios en Cuba. Especial referencia a la Necrópolis de Colón"; Arisyennis Yakelín Easy Porro, "El objeto de la propiedad estatal y dominio público del Estado en el derecho cubano"; Maydelis Ferraz Espinosa, "Insuficiencias de la propiedad cementerial en Cuba: apremiante necesidad de reglamentación”.

42 Resolución 114/07 sobre "las normas y procedimientos para la organización y funcionamiento del registro de la propiedad".

43 Cfr. artículo 81 de la Resolución 114/07, donde se establece que el registro de la propiedad se organiza de forma gradual en dos secciones, una urbana y otra rural. 
titulares, para que así no se obstaculice el tráfico jurídico, posibilitando con ello la publicidad registral y no se debilite consigo la seguridad jurídica para las personas naturales o jurídicas titulares de estos bienes.

\section{REFERENCIAS}

- Aries, Philippe. El hombre ante la muerte. Madrid: Taurus, 1984.

- "Breve historia de los cementerios". Acceso el 25 de diciembre de 2015. http://cultopia.es/ breve-historia-de-los-cementerios-ii/

- Cuenya, Miguel Ángel. "Los espacios de la muerte. De panteones, camposantos y cementerios en la ciudad de Puebla. De la Colonia a la Revolución”. Acceso el 19 de enero de 2016. https://nuevomundo.revues.org/15202

- Easy Porro, Arisyennis Yakelín. "El objeto de la propiedad estatal y dominio público del Estado en el derecho cubano". Tesis presentada en opción al título académico de licenciada en Derecho. Camagüey, 2009.

- Fernández Martínez, Martha. “Titulación efectiva, publicidad inmobiliaria y trasmisión por compraventa de los bienes funerarios en Cuba. Especial referencia a la Necrópolis de Colón”. Revista Cubana de Derecho (2013).

- Ferraz Espinosa, Maydelis. "Insuficiencias de la propiedad cementerial en Cuba: apremiante necesidad de reglamentación”. Tesis presentada en opción al título académico de licenciada en Derecho. Las Tunas, 2014.

- García Rondón, Caridad. "La protección jurídico-penal de los cementerios en Cuba". Tesis presentada en opción al grado académico de MS.c en Derecho Penal. Universidad de Matanzas, 2006.

- Gonzales Díaz, A. "El cementerio español de los ss. XVIII y XIX”. Archivo Español de Arte, n. ${ }^{\circ} 171$ (1970): 289-320.

- Nicolás Gómez, Dora. "La tratadística sobre botánica funeraria y el arbolado en los cementerios de Murcia en el s. XIX: a propósito de dos dibujos arquitectónicos en el Museo de Bellas Artes". Revista Verdolay, n.o 3 (1991): 189-192.

- Rivero Valdés, Orlando. Temas de derechos reales. La Habana: Ed. Félix Varela, 2005.

- Rodríguez Barberán, Francisco Javier. Los cementerios en la Sevilla contemporánea. Análisis histórico y artístico (1800-1950). Sevilla: Diputación Provincial de Sevilla, 1996. 
- Saguar Quer, Carlos. "Carlos III y el restablecimiento de los cementerios fuera del poblado". Fragmentos, n. ${ }^{o}$ 12-13-14 (1988).

“El cementerio del este de Barcelona”. Revista Goya, n. o 214 (1990): 210-219.

\section{LEGISLACIONES CONSULTADAS}

- Constitución de la República de Cuba, con las reformas de 1992, en Gaceta Oficial de la República de Cuba, Extraordinaria, No. 7, de 1 de agosto de 1992.

- Ley No. 59/1987 de 16 de julio, anotado y concordado con los ordenamientos cubano y español, por Ángel Acedo Penco y Leonardo B. Pérez Gallardo, Dykinson, Madrid.

- Ley No 6000 de 10 de noviembre de 1976, de Costa Rica.

- Ley No. 2 de 4 de agosto de 1977, Ley de los Monumentos Nacionales y Locales y su Reglamento.

- Ley de Cementerios y Servicios Funerarios e Perú, Ley No 26298 de 22 de marzo de 1994.

- Ley para la Regulación y Control de la Prestación de Servicio Funerario y Cementerios, No. 40.358 del 18 de febrero del 2014.Venezuela.

- Decreto Ley 704 de 7 de septiembre de 1949 "Regulación de la Propiedad y Arrendamiento de Tumbas en Cementerios, de Costa Rica”.

- Decreto No. 320 de 10 de mayo de 1973 "Ley General de Cementerios" de El Salvador.

- Decreto Supremo No. 39/1994 Reglamento de la Ley de Cementerios y Servicios Funerarios. Perú.

- Reglamento General de Cementerios, aprobado a través de la Ley No. 357 de 15 de mayo de 1970 de Chile.

- Reglamento de Servicios Funerarios del Instituto de Seguridad y Servicios Sociales de los Trabajadores del Estado de México y su Reglamento del Servicio Público de Panteones y Servicios Funerarios para el municipio de Hermosillo, Boletín Oficial No. 41, Sección 2 del 24 de mayo de 1999.

- Reglamento General de Cementerios, Decreto Ejecutivo No 32833, publicado en La Gaceta No 244 del 19 de diciembre de 2005, Costa Rica.

- Norma Oficial Mexicana nom-036-scfi-2007, prácticas comerciales - requisitos de información en la comercialización de servicios funerarios. 
- Reglamento para el Trabajo en las Funerarias, diciembre de 2007, Cuba.

- Reglamento para el Trabajo en los Cementerios, diciembre de 2007, Cuba.

- Reglamento Cementerial de la Necrópolis de Colón de 1948; versión de noviembre de 2011 del Anteproyecto de Decreto-Ley Cementerial, La Habana.

- Resolución No. 51 de 18 de febrero del año 1987, por la que la Comisión Nacional de Monumentos Nacionales y Locales le da el carácter de monumento nacional a la Necrópolis de Colón.

- Resolución 114/07 sobre "las normas y procedimientos para la organización y funcionamiento del registro de la propiedad".

- Resolución No. 1477 de 11 de mayo de 2009 del Ministerio de la Protección Social de la República de Colombia.

- Sentencia No 436 de 26 de diciembre de 2008 de la Sala de lo Civil y Administrativo del Tribunal Supremo Popular. Jueces Marta Acosta, Carlos Díaz, Isaura González. 


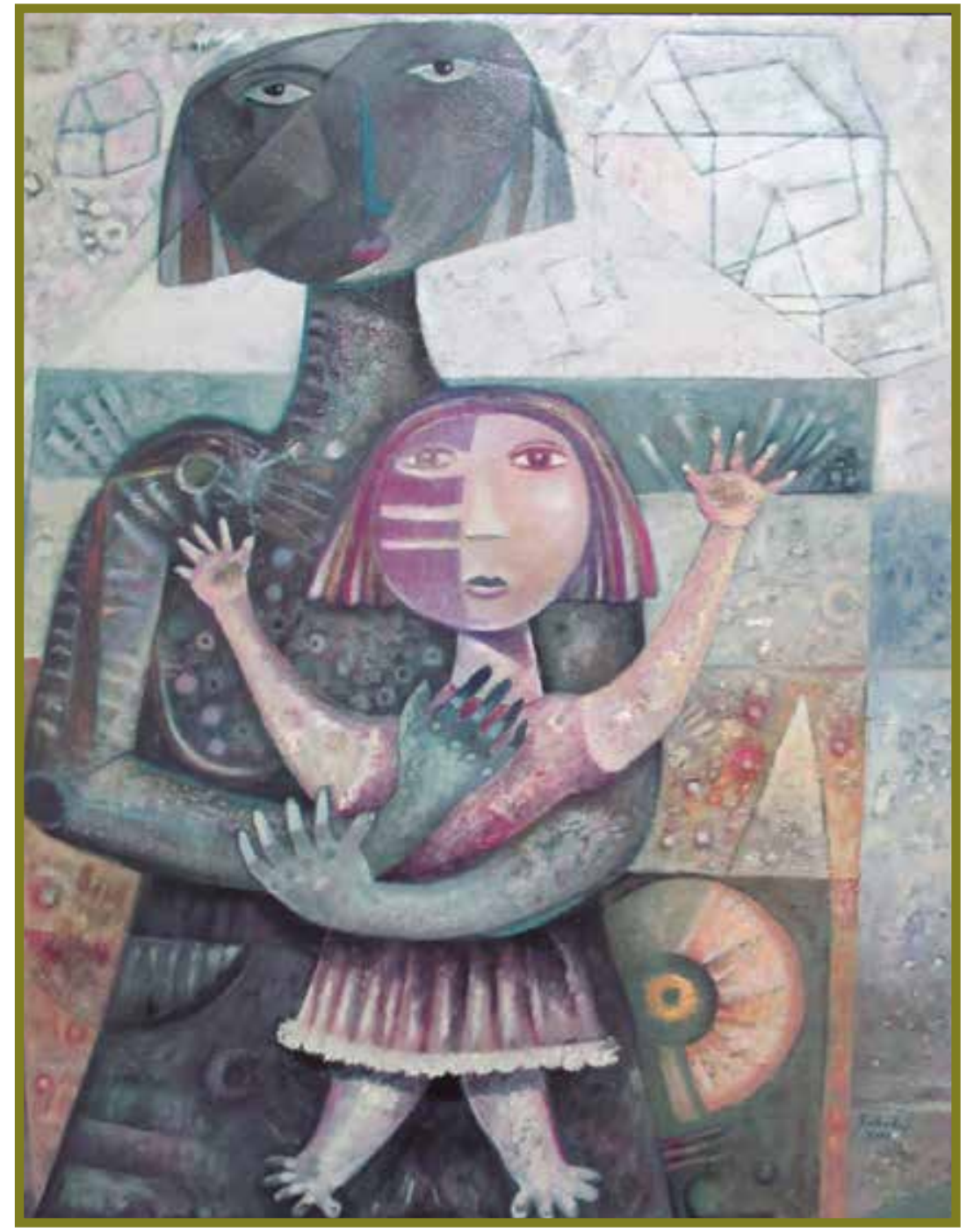

Ternura. Pintura. Juan Carlos Ñañake. 